\title{
Endometriosis Within the Rectus Muscle and Cesarean Scar: Analysis of 21 Cases and Assessment Potential of Malignancy
}

\section{Sezaryan Skarında ve Rektus Kası İçerisinde Görülen Endometriozis: 21 Olgunun Analizi ve Malignite Potansiyelinin Değerlendirilmesi}

\author{
Ahmet Karayiğit ${ }^{1}$, Mehmet Akif Üstüner ${ }^{1}$, Haluk Pulat ${ }^{2}$, Cihangir Özaslan ${ }^{1}$ \\ ${ }^{1}$ Dr.Abdurrahman Yurtaslan Ankara Onkoloji Eğitim Ve Araştırma Hastanesi,Genel Cerrahi Kliniği,Ankara \\ ${ }^{2}$ Dr.Abdurrahman Yurtaslan Ankara Onkoloji Eğitim Ve Araştırma Hastanesi,Patoloji Kliniği,Ankara
}

Dergiye Ulaşma Tarihi: 23.12.2016 Dergiye Kabul Tarihi: 16.01.2017 Doi: 10.5505/aot.2017.62634

\section{ÖZET}

Giriş ve Amaç: Endometriozis endometrium dokusunun uterus dışında başka bir anatomik bölgede bulunmasıdır. En sık overlerde olmak üzere batın içinde apendiksten karaciğere kadar her organda görülebilir. Sezaryan skarı(c/s) yada rektus kası içerisinde nadir olarak görülür.Bu çalışmada sezaryan skarı ve rektus kası içerisinde görülen 21 olgumuzu sunduk.

Yöntem ve Gereçler: 2008-2015 yılları arasında karın ön duvarındaki rektus kası içerisinde veya sezaryan skarında kitle nedeniyle opere ettiğimiz ve patoloji sonucu endometriozis olarak değerlendirilen hastaları retrospektif olarak inceledik.

Bulgular: Çalışmaya alınan kadın hastaların yaş ortalaması 34.5(24-52) olarak hesaplandı. Hastaların 11 'inde endometriozis dokusu eski sezaryan skarında, 9 hastada batın ön duvarında rektus kası içerisinde görülürken 1 hastada umbikal herni kesesi içerisinde gözlendi. Patoloji piyeslerindeki endometriozis kitlesinin ortalama büyüklüğü $3.4 \mathrm{~cm}(1.8 \mathrm{~cm}-7.5 \mathrm{~cm})$ olarak ölçüldü. Çalışmamızda hastaların 2'si genel anestezi altında 19'u lokal anestezi altında opere edildi. Hastaların 15'inde görüntüleme yöntemi olarak ultrason(USG) yapılırken, bu hastaların altısına USG sonrası ileri tetkik olarak manyetik rezonans(MR) tetkiki yapıldı. Hastalarda mortalite gözlenmezken, iki hastada yara yeri enfeksiyonu görüldü. Nüks gözlenmeyen hastalar halen takip ediliyor. Tartışma ve Sonuç: Endometriozis olguları sezaryan skarı ve karın ön duvarında nadir olarak görülmekte olup palpe edilebilen kitle ile birlikte ağrıya yol açar.Cerrahi eksizyon etkin bir tedavi yöntemidir. Nüksü engellemek için en az 1 cmlik cerrahi sınırla kitleyi çıkartmak gerekir.Batın ön duvarında ve sezaryan skarında kitle şikayeti ile gelen üreme çağındaki kadınlarda endometriozis akılda tutulmalıdır.

Anahtar Kelimeler: Endometriozis, Rektus Kası, Sezaryan Skarı

\begin{abstract}
Introduction: Endometriosis is characterized by the growth of endometrial tissue outside the uterus. Although it most frequently localized in the ovaries, it can affect every organ in the abdomen from the appendix to the liver. It is rarely seen in the cesarean scar(c/s) or rectus muscle. Herein, we report 21 case of endometriosis within the rectus muscle and cesarean scars.

Material and Methods: Between 2008 and 2015, a total of 21 patients who were operated for the mass within the rectus muscle or cesarean scar in the abdominal wall and whose pathological result was consisted with endometriosis were retrospectively analyzed.

Results: Median age of women in the study group was 34.5(24-52). Endometriosis localisation in 11 of the patients were found on the c/s scar, in 9 of them were on the rectus abdominis muscle, and one of them was in the umblical hernia sac. Median size of the endometriosis tissue was measured as $3.4 \mathrm{~cm}(1.8-7.5 \mathrm{~cm})$ in the specimens. In our study, 2 of the patients were given general anesthesia while 19 of them were operated under local anesthesia. Ultrasound imaging were done in all cases and 6 patients were further evaluated using magnetic resonance imaging(MRI). No mortality was reported. As for morbidity, 2 patient had local wound infection. Study group is followed up without any recurrence reported.

Discussion and Conclusion: Endometriosis cases are presented as palpable painful masses and rarely found on $\mathrm{C} / \mathrm{S}$ scar or on anterior abdominal wall. Surgery is a effective treatment option. To avoid any recurrence, masses must be removed a minumum $1 \mathrm{~cm}$ margin. In differential diagnosis of palpable and painful masses on the abdominal wall or $\mathrm{C} / \mathrm{S}$ scar in reproductive women, we should consider endometriosis.
\end{abstract}

Keywords: Endometriosis, rektus muscle, cesarean scar 


\section{Giriş}

Endometriozis endometriyal dokunun uterus dışında başka bir anatomik bölgede bulunmasıdır(1). İlk olarak 1860 yilında Avustralyalı patalog Karl Freiherr von Rokitansky tarafindan adenomiyom olarak tanımlanmıştır(2). Üreme çă̆ındaki kadınların yaklaşık \%6-\%10 kadarını etkiler,\%50-60 oranında pelvik ağrıya \%50 oranında infertiliteye sebep olabilir (3).

Endometriozis yerleşim yerine göre pelvik yada extrapelvik olarak ikiye ayrılır. Pelvik endometriozis daha sik görülmekte lup; overlerde, sakrouterin ligamanda, peritonal yüzde, fallop tüblerinde, üriner trackta, rektumda gözlenir. Extra pelvik endometriozis nadir görülmekte olup akciğer, mide, dalak, safra kesesi ve skar dokusunda gözlenmektedir (4,5). Skar endometriozisler \%0.03-\%1.08 oranında görülmekte olup genellikle jinekolojik operasyonlardan,özellikle sezaryanlardan sonra gözlenir (6-9). Rektus abdomis kas1 içerisinde endometriozis görülmesi oldukça nadir bir durum olup ilk olarak Ameto ve arkadaşları tarafindan 1984 yılında tarif edilmiştir (10).

Biz bu çalışmamızda sezaryan skarında ve rektus kası içerisinde kitleyle başvuran ve patoloji sonucu endometriozis olarak değerlendirilen extrapelvik yerleşimli 21 olgumuzu sunduk. Pelvik endometriozisler kadın doğum kliniklerince genellikle non-operatif şekilde tedavi edildiği ve birçoğuna doğumda yada laparoskopi sırasında tanı konulduğu için toplam endometriozis sayısına ulaşamadık.

\section{Yöntem ve Gereçler}

2008-2015 y1lları arasında karın ön duvarında rektus kası içerisinde veya sezaryan skarında kitle nedeniyle opere ettiğimiz ve patoloji sonucu endometriozis olarak değerlendirilen hastaları retrospektif olarak inceledik.

\section{Bulgular}

Çalışmaya alınan 21 kadın hastaların yaş ortalamas1 34.5(24-52) olarak hesapland1.
Hastaların 11'inde endometriozis dokusu eski sezaryan skarında, 9 hastada batın ön duvarında rektus kası içerisinde görülürken 1 hastada umbikal herni kesesi içerisinde gözlendi.

Patoloji piyeslerindeki endometriozis kitlesinin ortalama büyüklüğü 3.4 cm( $1.8 \mathrm{~cm}-7.5 \mathrm{~cm})$ olarak ölçüldü. Hastaların 2'si genel anestezi altında 19'u lokal anestezi altında opere edildi. Genel anestezi alan hastalardan biri umbikal herni diğeri akut batın(akut apendisit?) ön tanılarıyla operasyona alındı.Hastaların 15 'inde görüntüleme yöntemi olarak ultrason(USG) yapilırken, bu hastaların altısina USG sonrası ileri tetkik olarak manyetik rezonans tetkiki(MR) yapıldı(Tablo 1). Hastalarda mortalite gözlenmezken, iki hastada yara yeri enfeksiyonu görüldü. Nüks gözlenmeyen hastalar halen takip ediliyor.

\section{Tartışma ve Sonuç}

Kadınların yaklaşık olarak \%11'i endometriozisle karşılaşmaktadır ancak gerçek prevelans1 belirlemek güçtür(11-14). Endemotriozisin gelişiminde 3 önemli teori öne sürülmüştür. Birinci teoride endometrial hücreler hematojen yolla, lenfatik yolla yada cerrahi işlemlerle çevre dokulara göç etmektedir (metastatik teori). İkinci teoride primitif pluripotent mezenkimal hücreler farklılaşıp zamanla endometrial dokuya dönüşür (metaplastik teori). Üçüncü teoride endometrial dokular menstruasyon döneminde retrograt olarak pelvise göç ede $\mathrm{r}(5,15-17)$.

Skar dokusunda ve rektus kası içerinde gözlenen endometriozis olgularımızın \%76'sinda sezaryan operasyonu öyküsü mevcut.Bu yüzden bizim olgularımızdaki endometriozis gelişiminin daha çok birinci teorideki gibi cerrahi manuplasyonlarla, iatrojenik olarak gerçekleştiğini düşünüyoruz. Doğum sonrası uterusun kapatılması esnasında endometriumun yeterince içeri inverte edilememesi bu olayın bir sebebi olabilir. Amniosentez sirasında iğnenin ilerlediği yol boyunca endometriozis gözlenmesi de birinci teoriyi destekler niteliktedir(18). 
Tablo 1:Opere edilen kitlelerin,yerleşim yerleri,boyutları,yapılan operasyonları ve radyolojik bulguları

\begin{tabular}{|c|c|c|c|c|c|c|c|c|}
\hline $\mathrm{NO}$ & YAŞ & $\begin{array}{l}\text { YERLEŞIM } \\
\text { YERİ }\end{array}$ & BOYUT & OPERASYON & $\begin{array}{l}\text { İLK } \\
\text { OPERASYON }\end{array}$ & USG & BT & MR \\
\hline 1 & 28 & $\begin{array}{l}\text { Sezaryan } \\
\text { skar1 }\end{array}$ & $2 \mathrm{~cm}$ & Total eksizyon & Sezaryan & - & - & - \\
\hline 2 & 24 & $\begin{array}{l}\text { Rektus kası } \\
\text { arasında }\end{array}$ & $4 \mathrm{~cm}$ & Total eksizyon & --- & pozitif & - & pozitif \\
\hline 3 & 29 & $\begin{array}{l}\text { Sezaryan } \\
\text { skarı }\end{array}$ & $2.5 \mathrm{~cm}$ & Total eksizyon & Sezaryan & pozitif & - & - \\
\hline 4 & 41 & $\begin{array}{l}\text { Sezaryan } \\
\text { skarı }\end{array}$ & $3.5 \mathrm{~cm}$ & Total eksizyon & Sezaryan & pozitif & - & - \\
\hline 5 & 37 & $\begin{array}{l}\text { Rektus kası } \\
\text { arasında }\end{array}$ & $4 \mathrm{~cm}$ & Total eksizyon & Sezaryan & pozitif & - & - \\
\hline 6 & 32 & $\begin{array}{l}\text { Rektus kası } \\
\text { arasında }\end{array}$ & $2.7 \mathrm{~cm}$ & Total eksizyon & - & pozitif & pozitif & - \\
\hline 7 & 25 & $\begin{array}{l}\text { Rektus kası } \\
\text { arasında }\end{array}$ & $4 \mathrm{~cm}$ & Total eksizyon & Sezaryan & pozitif & - & - \\
\hline 8 & 36 & $\begin{array}{l}\text { Sezaryan } \\
\text { skarı }\end{array}$ & $1.8 \mathrm{~cm}$ & Total eksizyon & Sezaryan & pozitif & - & pozitif \\
\hline 9 & 33 & $\begin{array}{l}\text { Rektus kası } \\
\text { arasında }\end{array}$ & $2 \mathrm{~cm}$ & Total eksizyon & - & - & - & - \\
\hline 10 & 31 & $\begin{array}{l}\text { Sezaryan } \\
\text { skarı }\end{array}$ & $2 \mathrm{~cm}$ & Total eksizyon & Sezaryan & - & - & - \\
\hline 11 & 29 & $\begin{array}{l}\text { Sezaryan } \\
\text { skar1 }\end{array}$ & $4 \mathrm{~cm}$ & Total eksizyon & Sezaryan & pozitif & - & pozitif \\
\hline 12 & 37 & $\begin{array}{l}\text { Rektus kası } \\
\text { arasında }\end{array}$ & $6.6 \mathrm{~cm}$ & Total eksizyon & Sezaryan & pozitif & - & pozitif \\
\hline 13 & 29 & $\begin{array}{l}\text { Sezaryan } \\
\text { skar1 }\end{array}$ & $2 \mathrm{~cm}$ & Total eksizyon & Sezaryan & pozitif & - & - \\
\hline 14 & 52 & $\begin{array}{l}\text { Umbikal } \\
\text { herni kesesi } \\
\text { içerisinde }\end{array}$ & $7.5 \mathrm{~cm}$ & $\begin{array}{l}\text { Primer Herni } \\
\text { tamiri }\end{array}$ & - & pozitif & - & - \\
\hline 15 & 37 & $\begin{array}{l}\text { Rektus kası } \\
\text { arasında }\end{array}$ & $5.3 \mathrm{~cm}$ & Total eksizyon & Sezaryan & pozitif & - & pozitif \\
\hline 16 & 34 & $\begin{array}{l}\text { Sezaryan } \\
\text { skar1 }\end{array}$ & $4.5 \mathrm{~cm}$ & Total eksizyon & Sezaryan & pozitif & - & - \\
\hline 17 & 32 & $\begin{array}{l}\text { Sezaryan } \\
\text { skar1 }\end{array}$ & $2 \mathrm{~cm}$ & Total eksizyon & Sezaryan & pozitif & - & - \\
\hline 18 & 38 & $\begin{array}{l}\text { Rektus kası } \\
\text { arasında }\end{array}$ & $3.7 \mathrm{~cm}$ & Total eksizyon & - & pozitif & - & pozitif \\
\hline 19 & 36 & $\begin{array}{l}\text { Rektus kası } \\
\text { arasında }\end{array}$ & $2.5 \mathrm{~cm}$ & Total eksizyon & Sezaryan & - & - & - \\
\hline 20 & 37 & $\begin{array}{l}\text { Sezaryan } \\
\text { skarı }\end{array}$ & $3 \mathrm{~cm}$ & Total eksizyon & Sezaryan & - & - & - \\
\hline 21 & 49 & $\begin{array}{l}\text { Sezaryan } \\
\text { skar1 }\end{array}$ & $2 \mathrm{~cm}$ & Total eksizyon & Sezaryan & - & - & - \\
\hline
\end{tabular}

Aynı zamanda ilk operasyonla lezyonun ortaya çıkış zamanı arasındaki zaman dilimi bir çok seride 3 ay ile 10 yıl arasında değiştiği bildirilmiştir(19). Çalışmamız retrospektif olduğu için bu zaman dilimi net olarak değerlendirilememiştir. 
Extrapelvik ve intrapelvik endometriozis arasındaki ilişki net değildir. Garwood ve arkadaşları extrapelvik endometriozisli hastaların \%26'sinda ayn1 zamanda intrapelvik endometriozis geliştiğinden bahsetmektedir (14). Bizim olgularımızın hiç birinde intrapelvik endometriozis saptanmadi.

Endometriozisli hastalar genellikle menstruel dönemde gelişen siklik ağrıdan şikayet eder. Ancak skar endometriozislerde ağr1 atipiktir (11). Hastalarda devamlı ağr1 şikayeti olabileceği gibi,hiç ağrı olmadan ele gelen kitle ile de hastaneye başvurabilirler. Çalışmamızda hastaların birçoğu daha önce en az bir kez non-streoid antiinflamatuar tedavi almış, ancak sonuç alamamışlardır. Endometriozis ağrısı akut batın tablosunu da taklit edebilir yada umbikal bölgeye yerleşip herni görüntüsü verebilir $(20,21)$. Bizim serimizdeki genel anestezi altında opere edilen hastalardan biri umbikal herni (no:14), diğeri akut apendisit (no:15) ön tanılarıla operasyona alındilar.

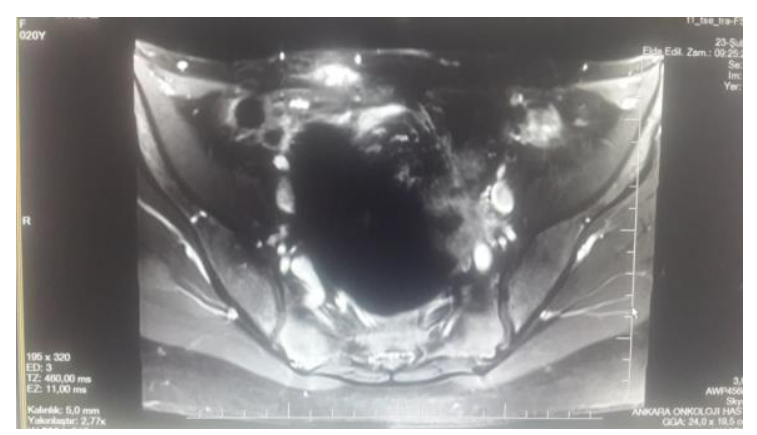

Şekil 1: Rektus kası lateralinde endometriozis dokusunun IV kontrastlı MR tetkikinde hipointens sinyalle karekterize görüntüsü

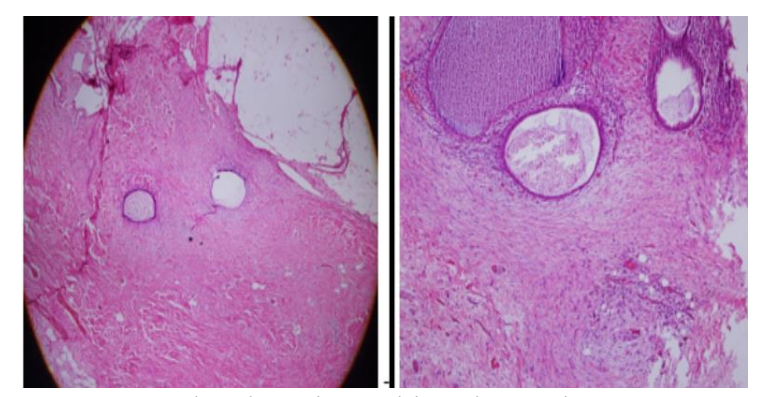

Şekil 2: Çıkarılan piyesteki endometrium dokusunun Hemotoksilen Eozinle boyanmıs 400 büyütmedeki görüntüsü(A) Endometrium dokusu etrafındaki enflamasyon ve kanama alanlarının Hemotoksilen Eozinle boyanmış 200 büyütmedeki görüntüsü(B).
Hastalar abdominal duvar abseleri, hematom, lipom, sütur granülomu, kist sebase,desmoid tümör, sarkom, lenfoma, primer ve sekonder metastatik kanser ve hernilerle karışatırılabilir(22). Hasta için seçilecek cerrahinin genişliği ve operasyon öncesi doğru tarama ve evreleme yapabilmek için batın ön duvarı primer ve metastatik tümörleri mutlaka akılda tutulmalıdır. Endometriozisin malign potansiyel riski çok bilinmez ve \% 1'in altındadır. Malignite geliştiği zaman genellikle clear cell carcinoma olarak karşımıza çıkar ve 5 yıllık sağkalımı yaklaşık olarak \%80'dir(28-29). Bizim çalışmamızdaki hastaların ortalama 3 yıllık takiplerinde malignite saptanmad.

Görüntüleme yöntemi olarak ultrason (USG), batın tomografisi (BT) ve manyetik rezonans (MR) kullanılabilir. Ultrasonda spesifik bir bulgu yoktur lezyonlar kistik, solid yada miks olabilir; ancak BT ve MR yüksek sensivite (\%90-92) ve yüksek spesiviteye sahiptir (\%91-98) (23-25).

Bizim çalışmamızda 15 hastaya (\%71) USG, 1 (\%5) hastaya BT, USG sonuçlarında şüpheli lezyonları bulunan 6 hastaya (\%28) MR tercih edildi (Figure: 1 ).

Görüntüleme yöntemleri dışında tanı için ince iğne aspirasyon biyopsisi kullanılabilir. Ancak duyarlılığı yine de $\% 100$ olmaz ve endometriozisin yayılmasina neden olabilir(26). Kesin tanı patolojik olarak mikroskop altında çıkarılan piyeste endometrium dokusunun görülmesiyle konulur (Figure 2).

Endometriozis tanisinda kanser antijen125(CA-125),C-reaktif protein(CRP), anti müllerien hormon, follistatin gibi biyokimyasal belirteçler daha önceki çalışmalarda faydalı bulunmuştur. Bizim olgularımızda sinırlı sayıdaki hastalarda bakılan CA-125 değerleri normal olarak değerlendirildi. Yapılan güncel çalışmalarda düşük vücut kitle indeksi (BMI)'ne sahip kadınların endometriozis için yüksek riske sahip olduğu belirtilmiştir(27). Bizim serimizde sınırlı sayıda ölçülen BMİ'de böyle bir sonuca ulaşılamamıştır.

Sezaryan skarı yada batın ön duvarındaki endometriozisler için etkin tedavi cerrahi rezeksiyondur.Nüksü engellemek için en az 1 cmlik temiz cerrahi sinırla total olarak eksizyon yapılmalıdır(30). Cerrahinin yanı sıra ağrının etkisini ve süresini azaltmak için 
medikal tedavi uygulanabilir.Medikal terapi olarak non-steroidal anti-inflamatuarlar, oral kontraseptivler, aramatöz inhibitörleri , gonadotropin salgilatan hormon $(\mathrm{GnRH})$ analogları kullanılabilir. Radyofrekans ablasyon da alternatif bir tedavi seçeneğidir(31).

Sonuç olarak eski sezaryan skarında yada batın ön duvarında ağrılı kitle ile başvuran, fertil çağdaki kadınlarda endometrızis akılda tutulmalıdır. Akut batın, umbikal herni gibi

\section{Referanslar}

1. Goel P, Sood SS, Romilla, Dalal A. Cesarean scar endometriosis - Report of two cases. Indian J Med Sci. 2005;59(11):495-498.

2. Khamechian T,Alizargar J,Mazoochi T.5-Year data of patients following abdominal wall endometrioma surgery.BMC Women's Healt. 2014;14:151.

3. 3.Giudice LC.Endometriosis.N Engl J Med. 2010;362:2389-98.

4. Douglas C, Rotimi O. Extragenital endometriosis a clinico pathological review of a Glasgow hospital experience with case illustrations. J Obstet Gynaecol.2004;24:804-808.

5. Woodward PJ,Sohaey R,Mezzetti TP. Endometriosis: radiologic-pathologic correlation .Radiographics. 2001;21:193-216.

6. Çöl C,Yılmaz EE.Cesarean scar endometrioma:Case Series.World J Clin Cases.2014;2(5):133-136.

7. Teng CC, Yang HM, Chen KF, Yang CJ, Chen LS, Kuo CL.Abdominal wall endometriosis: an overlooked but possibly preventable complication. Taiwan J Obstet Gynecol.2008; 47:42-48.

8. Gunes M, Kayikcioglu F, Ozturkoglu E, Haberal A. Incisional endometriosis after cesarean section, episiotomy and other gynecologic procedures. J Obstet Gynaecol Res .2005; 31:471-475.

9. Hensen JH, Van Breda Vriesman AC, Puylaert JB. Abdominal wall endometriosis: clinical presentation and imaging features with emphasis on sonography. AJR Am J Roentgenol.2006; 186:616-620.

10. Amato M,Levitt R.Abdominal wall endometrioma: CT findings. J Comput Assit Tomogr. 1984 Dec;8(6):1213-1214.

11. Solak A,Genç B,Yalaz S,Şahin N,Sezer TÖ,Solak İ. Abdominal Wall Endometrioma:Ultrasonographic Features and Correlation with Clinic Findings.Balkan Med.J.2013;30:155-160.

12. Bachir JS, Bachir NM. Scar endometrioma: awareness and prevention. WMJ.2002;101:46-49.

13. Buck Louis GM, Hediger ML, Peterson CM,et al.Incidence of endometriosis by study population and diagnostic method: the ENDO study. Fertil Steril.2011;96:360-365. farklı klinik presentasyon gösterebilir. Sensivite ve spesivitesi en yüksek tetkik olan MR, endometrızisin ayırıcı tanısında fikir verebilir. Malignite riski her zaman akılda tutularak ,olas1 nüksünde önüne geçmek için en az $1 \mathrm{cmlik}$ cerrahi sınırla çıkartılmaldır. Özellikle jinekolojik vakalarda endemetriumun batın duvarıyla iatrojenik teması engellenmelidir.

14. Garwood E, Kumar A, Moes Gregory. Abdominal scar endometrioma mimicking incisional hernia.Published Online: Wednesday,August 8, 2007.

http://www.hcplive.com/publications/surgicalrounds .Accessed August 8, 2007.

15. Aimakhu VE. Anterior abdominal wall endometriosis complicating a uteroabdominal sinus following classical cesarean section. Int Surg .1975; 60: 103104.

16. Singh KK, Lessells AM, Adam DJ,et al.Presentation of endometriosis to general surgeons: a 10-year experience. Br J Surg.1995; 82: 1349-1351.

17. Tanrıkulu Y,Temiz A,Özmen SA,Aslan OB. Skar endometriozis:3 olgu sunumu ve literatürün gözden geçirilmesi.Genel T1p Derg.2013;23(2):59-62.

18. Kauntz A, Di Sant'Agnese PA. Needle tract endometriosis: an unusual complication of amniocentesis. Obstet Gynecol.1979; 54:753-755.

19. Gupta P,Gupta S. Scar Endometriosis:a Case Report with Literature Review.Acta Medica Iranica.2015;53:12.

20. Ulucanlar H,Agaç A,Kutun S,Demir A,Çetin A.Rectus Abdominis Endometrioma Mimicking Acute Abdomen.Kocatepe Tip Dergisi.2008;9:1. 